\title{
ANALISIS INCREMENTAL KELAYAKAN PENAMBAHAN LINI PERAKITAN ENGINE MOTOR PT ABC
}

\author{
Jonny \\ Industrial Engineering Department, Faculty of Engineering, Binus University \\ Jl. K.H. Syahdan No. 9, Palmerah, Jakarta Barat 11480 \\ jonny@binus.ac.id
}

\begin{abstract}
Manufacturing motorcycle unit in Plant 1 of PT ABC requires engine supply from Plant 2. This has some burden on the operating cost of Plant 1 and the opportunity loss as well due to delay of motor engine delivery. Based on the problem, team proposes additional engine line in Plant 1 to cut engine supply from Plant 2. Therefore, team analyzes this proposal using incremental analysis to determine whether the proposal is feasible or not by comparing before and after condition with result NPV about IDR 967 Billion and Payback Period under 1 year. By this result, team determines that this proposal is recommended to be approved by management.
\end{abstract}

Keywords: motorcycle unit manufacture, Manufacturing motorcycle unit, incremental analysis, engine line

\begin{abstract}
ABSTRAK
Produksi unit motor di Plant 1 dari PT ABC memerlukan pengiriman engine dari Plant 2. Hal ini dapat membebani biaya operasional Plant 1 di samping adanya kemungkinan kerugian karena tidak terpenuhinya kebutuhan engine motor secara tepat waktu. Tim mengajukan penambahan lini perakitan engine motor yang diharapkan dapat memutus rantai pasok dari Plant 2 dan menjadikan Plant 1 sebagai plant mandiri yang dapat memenuhi kebutuhannya sendiri. Untuk itu perlu dilakukan analisis incremental atas kelayakan penambahan lini perakitan engine motor dengan membandingkan kondisi sebelum dan sesudah di mana hasilnya NPV mencapai Rp 967 Milyar dengan payback period di bawah satu tahun. Dari hasil ini dapat disimpulkan bahwa proposal lini perakitan engine motor ini dapat diterima.
\end{abstract}

Kata kunci: produksi unit motor, pengiriman engine, analisis incremental, lini perakitan 


\section{PENDAHULUAN}

Saat ini, Plant 1 PT ABC hanya memiliki satu lini dengan kapasitas 2600 unit per hari dengan waktu siklus yang lebih pendek dan tenaga kerja yang lebih banyak. Untuk memenuhi kebutuhan lini perakitan unit motor sebesar 3400 unit perhari, Plant 1 harus menambah 800 unit per hari dari Plant 2 dengan rata-rata tingkat stock sebesar 1,200 unit engine.

Waktu siklus yang pendek dengan tenaga kerja yang lebih banyak dapat menyebabkan timbulnya masalah potensial pada baik pada mutu, kesehatan dan keselamatan kerja. Hal ini terlebih dikarenakan operator harus bekerja di ruang kosong yang sangat sempit yaitu 0.8 meter dari standar 1 meter yang diharuskan.

Dengan meningkatnya harga solar, maka transportasi unit engine yang terlalu sering dari Plant 2 ke Plant 1 dapat meningkatkan biaya transportasi. Sementara itu, karena adanya kemacetan lalu lintas di sekitar Plant 2 dan Plant 1 dapat menyebabkan makin lamanya lead time yang dibutuhkan agar unit engine tersebut sampai ke Plant 1. Untuk mengantisipasi lead time ini, Plant 1 harus meningkatkan tingkat stoknya yang tentunya dapat meningkatkan area penyimpanan lebih luas dan pada gilirannya akan menyebabkan terjadinya idle fund karena tingginya tingkat stock ini. Oleh karena itu, Plant 1 bermaksud untuk menambah lini perakitan engine motor dapat memutuskan rantai pasok dari Plant 2 ke Plant 1. Namun demikian untuk melakukan hal ini, Plant 1 membutuhkan anggaran yang perlu dianalisis kelayakannya.

Dari uraian di atas, tujuan dari penelitian ini adalah untuk menentukan apakah proposal ini dapat diterima atau ditolak dengan menggunakan analisis incremental berdasarkan perolehan NPV dan Pay Back Period dari propoosal yang diajukan.

Dengan demikian diharapkan hasil penelitian ini dapat digunakan oleh manajemen dalam menentukan kelayakan dari proposal ini di samping manfaatnya sebagai referensi dalam menilai kelayakan suatu proposal.

\section{METODE}

Metode yang digunakan adalah analisis incremental (William, 2010) di mana tim menghitung cost yang diderita dengan kondisi saat ini kemudian tim menghitung cost (Webster, 2010) apabila proposal diterima. Selanjutnya, kedua cost ini dianalisis untuk diperoleh incremental cost yang terjadi. Hasilnya dianalisis NPV (Sullivan, 2009) untuk melihat profitabilitas proposal selama umur project. Adapun bagan selengkapnya dapat ditujukan dalam bagan berikut (Gambar 1). 


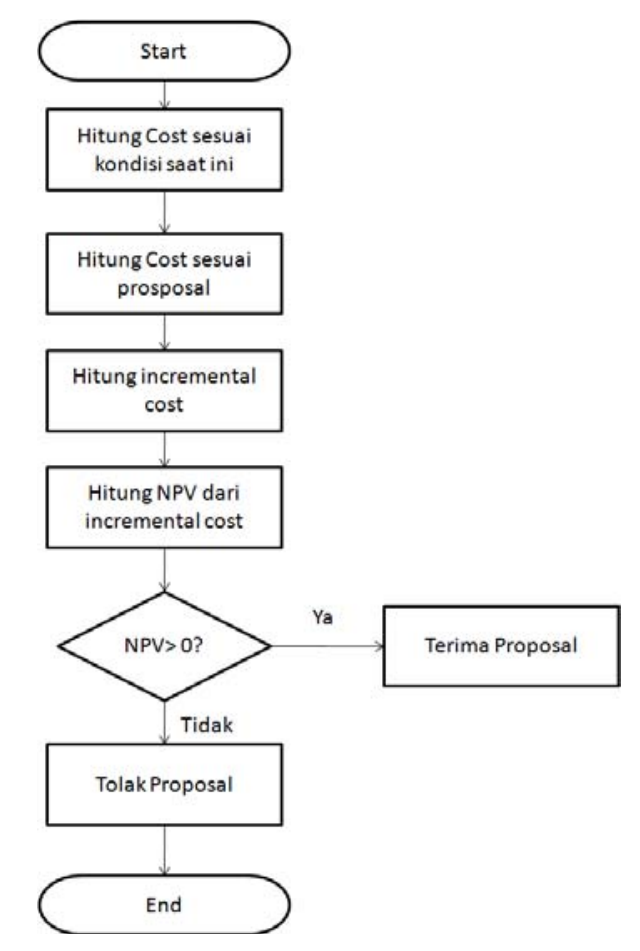

Gambar 1 Metodologi penelitian

\section{HASIL DAN PEMBAHASAN}

Dalam memproduksi satu unit motor, diperlukan dua proses utama yaitu dari sisi perakitan engine dan frame. Untuk perakitan engine dapat dilihat secara detail pada Gambar 2 sebagai berikut.

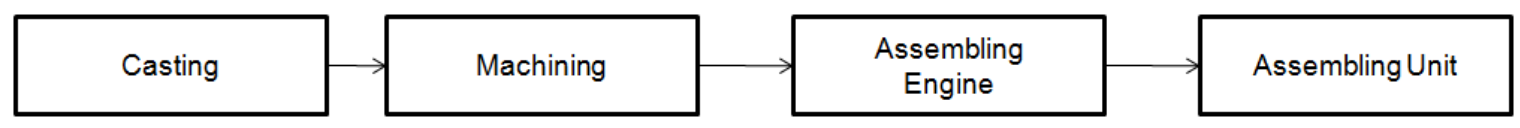

Gambar 2 Proses perakitan unit motor

Gambar di atas memberikan gambaran kepada kita bahwa untuk dapat merakit satu unit motor maka diperlukan engine. Saat ini, agar Plant 1 dapat memproduksi 3400 unit per hari (AF Plant 1), maka Plant 1 membutuhkan pengiriman dari Plant 2 sebanyak 800 unit per hari dengan didukung tingkat stok sebesar 1200 unit per hari seperti yang digambarkan pada Gambar 3. Kondisi seperti yang digambarkan di atas telah menimbulkan biaya per tahun yang tidak sedikit seperti yang dirinci pada Tabel 1 berikut. Dari tabel di atas, dapat kita simpulkan bahwa total biaya operasional yang harus ditanggung oleh Plant 1 mencapai Rp 12,2 Miliar per tahunnya. Melihat kondisi di atas, tim bermaksud mengajukan proposal untuk menambah lini perakitan engine di Plant 1 dengan kondisi sesuai Gambar 4. 


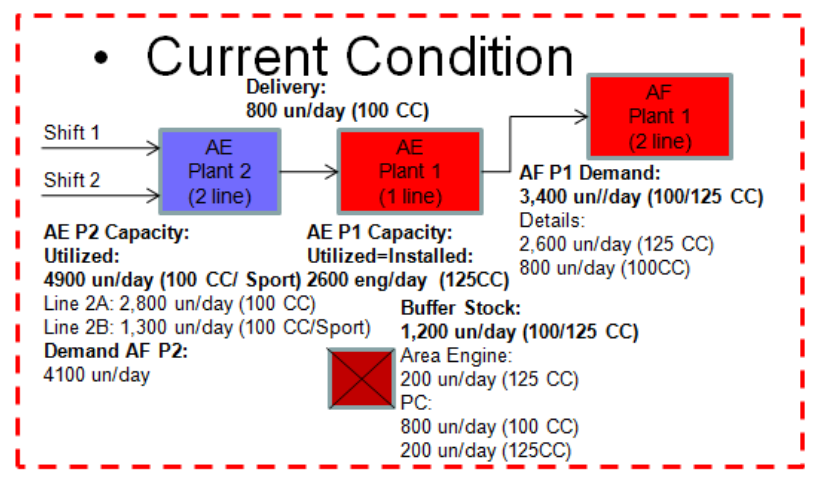

Gambar 3 Kondisi saat ini

Tabel 1Perhitungan Cost Kondisi Saat Ini

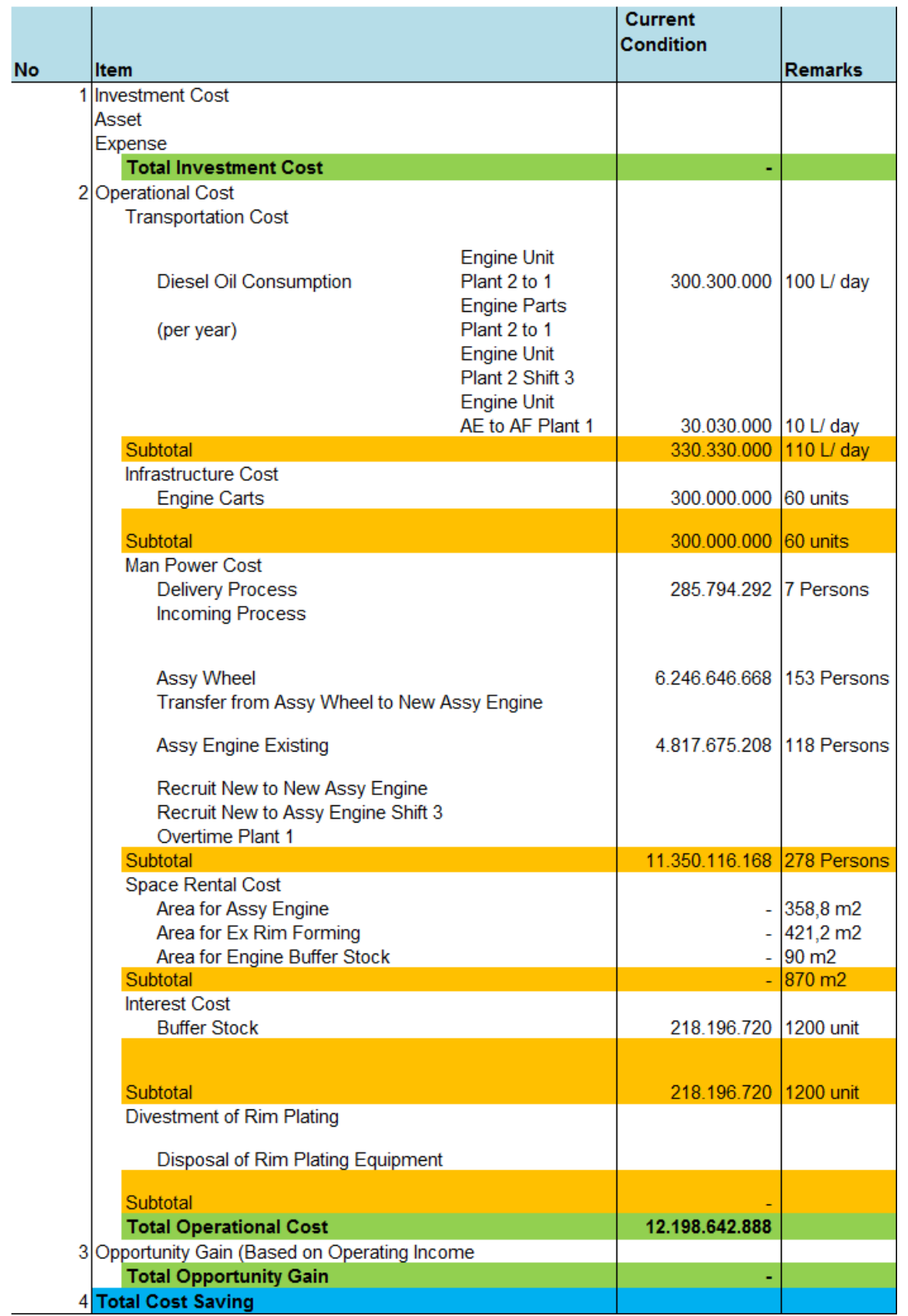




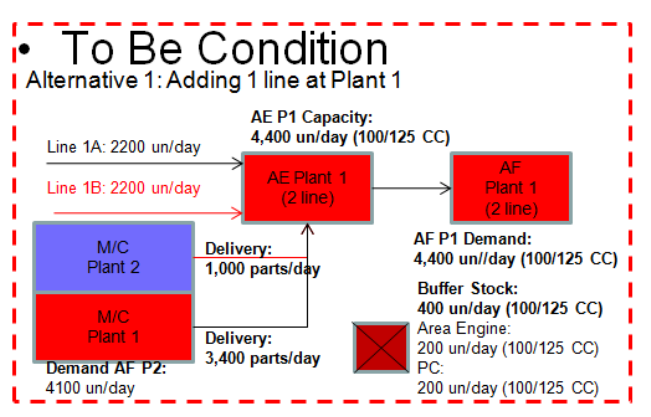

Gambar 4 Kondisi sesuai proposal

Kondisi di atas dapat diperoleh incremental cost seperti yang ditunjukkan pada Tabel 2. Tabel 2 menunjukkan adanya incremental cost yang diperoleh dari meningkatnya tambahan engine apabila ada tambahan lini perakitan engine. Dari Tabel 3, dapat kita ketahui bahwa secara operasional terdapat cost saving disisi transportation cost. Karena proposal untuk menambah lini perakitan engine memerlukan tambahan tenaga kerja, operational cost terlihat bertambah. Namun demikian, diperoleh tambahan pendapatan karena adanya tambahan engine. Selanjutnya incremental cost ini dianalisis menggunakan NPV dengan detail sebagai berikut (Tabel 4). Tabel 4 menunjukkan bahwa NPV sesuai proposal lebih besar dari nol sehingga dapat disimpulkan bahwa proposal dapat diterima khususnya dengan payback period di bawah satu tahun.

Tabel 2 Perhitungan Cost Sesuai Proposal

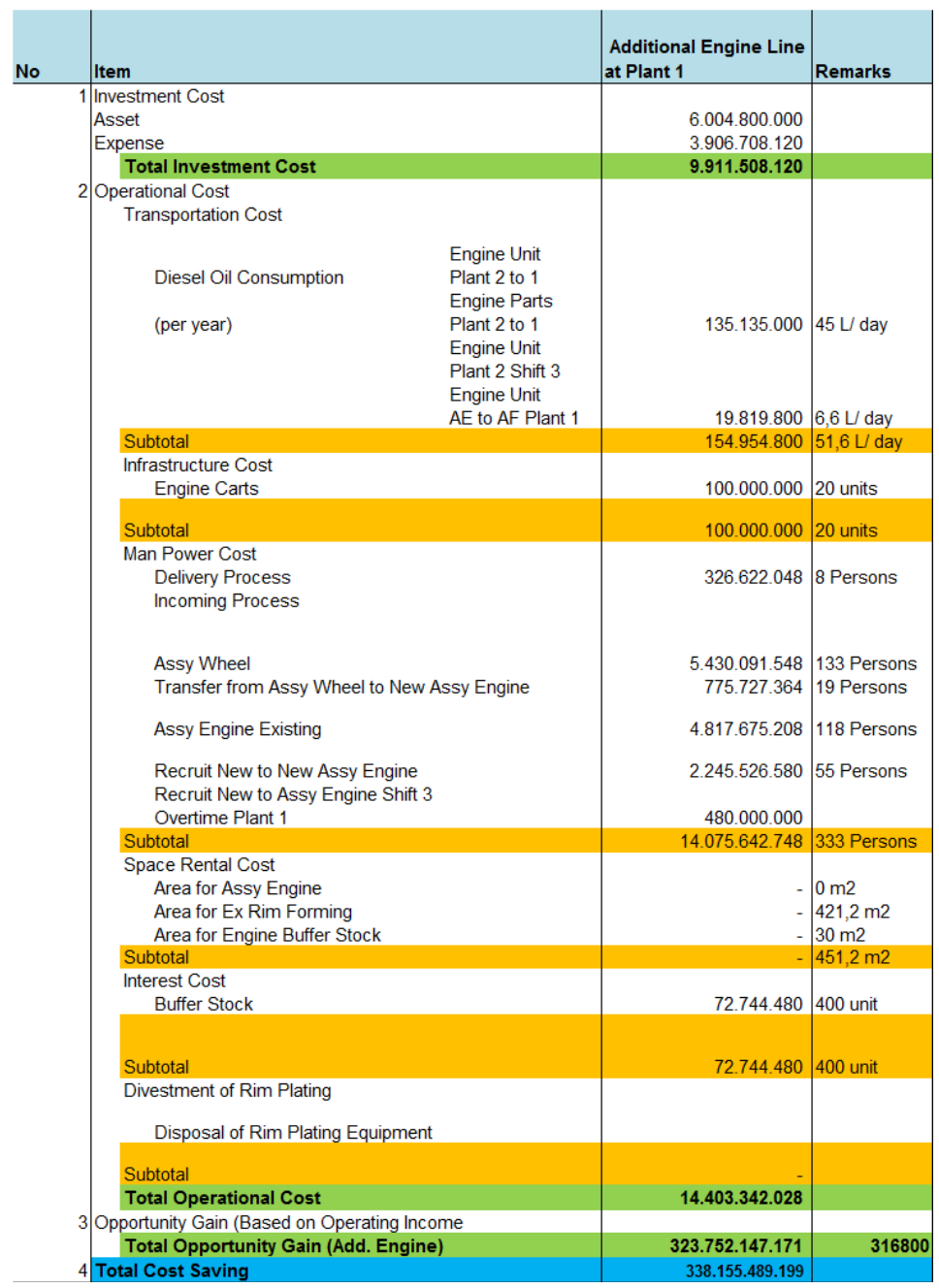


Tabel 3 Perhitungan Incremental Cost

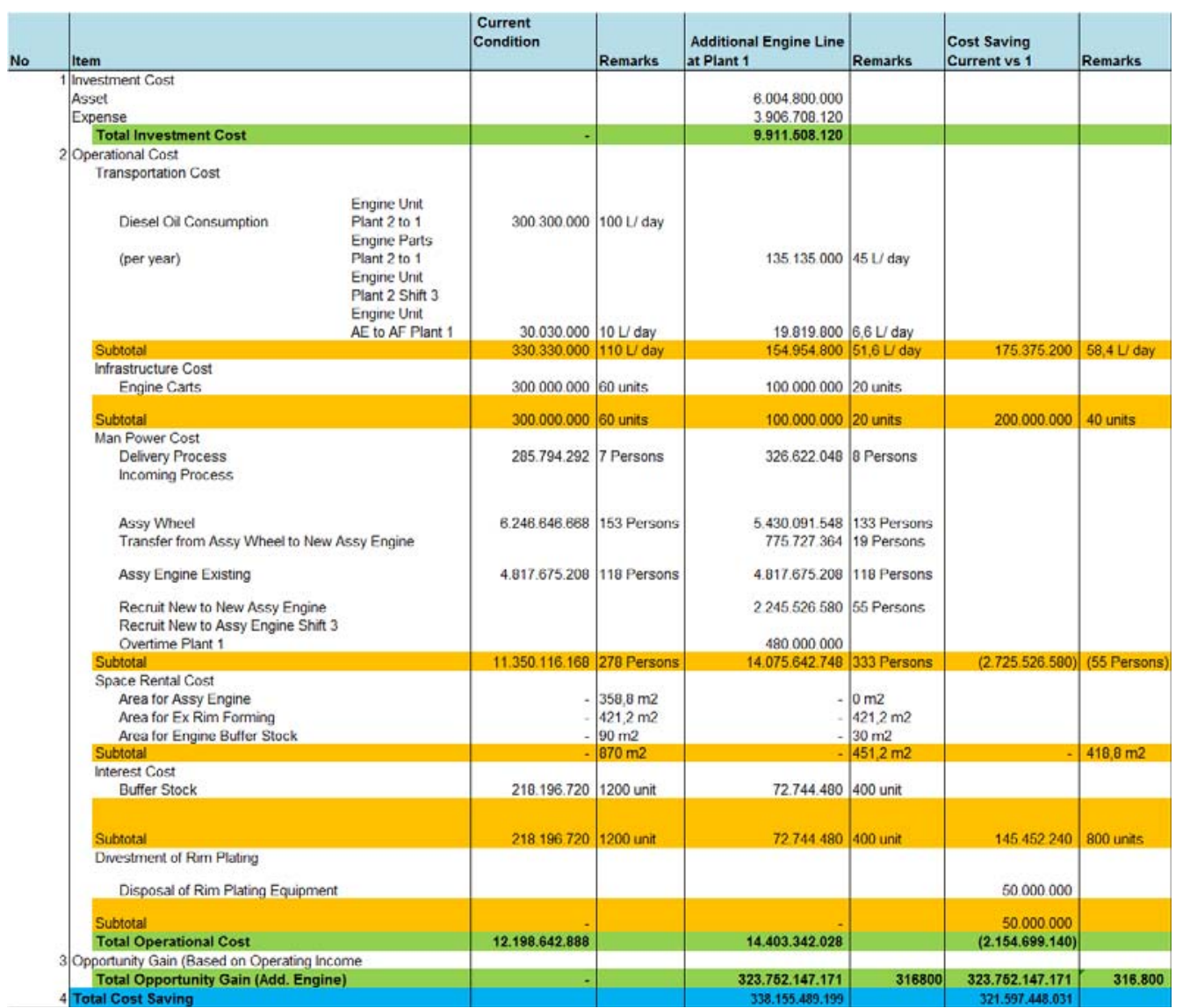

Tabel 4 Perhitungan NPV

\begin{tabular}{|c|c|r|r|r|r|}
\hline Alternative & NPV & EVA & $\begin{array}{l}\text { Pay Back } \\
\text { Period }\end{array}$ & IRR & \multicolumn{1}{|c|}{$\begin{array}{l}\text { Profitability } \\
\text { Index }\end{array}$} \\
\hline $\begin{array}{c}\text { Alternative 1: Adding 1 line at } \\
\text { Plant 1 (Cap 4400/ day) }\end{array}$ & Rp967.415.657.943 & Rp1.779.233.971.402 & & & \\
\hline
\end{tabular}

\section{SIMPULAN}

Berdasarkan hasil analisis incremental yang telah dilakukan, diambil simpulan bahwa proposal penambahan engine dapat diterima karena nilainya lebih besar dari nol dengan payback period di bawah satu tahun.

\section{DAFTAR PUSTAKA}

Sullivan, W.G., Wicks, E.M., \& Patrick, K.C. (2009). Engineering Economy. New Jearsey: Pearson Prentice Hall.

Webster, William H. (2004). Accounting for Managers. New York: McGraw-Hill.

Williams, Haka dan Bettner, Carcello. (2010). Financial and Managerial Accounting: The Basis for Business Decision. New York: McGraw-Hill. 